\title{
Da genômica nutricional ao interactome network disease: a nutrição sob um novo olhar
}

- A ciência da Nutrição vem evoluindo constantemente nos últimos cem anos, e com esta evolução, também surgem as novas possibilidades de terapêutica e tratamento dos indivíduos, a busca por uma melhor qualidade de vida e por uma visão mais humana e voltada para a individualidade dos processos metabólicos, sociais e comportamentais, possibilitando a criação e a utilização de técnicas e ferramentas que vem colocando a nutrição como a uma das ciências mais importantes do século;

- Vislumbramos no Brasil, desde o início da criação dos primeiros cursos com o pioneirismo de Pedro Escudeiro e na atualidade com o guia alimentar da população brasileira (publicado em 2014 e apontado como uma referência mundial em orientação à população de uma nutrição de qualidade), o grande potencial da nutrição como ciência da saúde no país e no mundo. Começamos a nutrição com abordagem terapêutica, com cálculo de calorias, contagem de carboidratos e chegamos na atualidade com a possibilidade de deciframos rotas metabólicas, polimorfismos genéticos (pequenas variações dos genes encontradas nos indivíduos) e individualizar a dieta a tal ponto que isso implica até mesmo em mudanças da fertilidade e no aumento da performance de atletas de elite;

- Essa visão prática e contemporânea da nutrição, utilizando abordagens como a nutrição cognitivo comportamental e a busca pelo entendimento da influência da alimentação na programação metabólica dos primeiros mil dias de uma criança, além da construção de ferramentas como a teia nutricional e softwares voltados para cálculos nutricionais, somados ao estudo da nutrição como uma rede de informações onde é avaliada a interação entre os genes e as doenças (Interactome Network Disease) ou até mesmo a utilização de CRISPR (Repetições Palindrômicas Curtas Agrupadas Regularmente e Interespassadas), que podem interferir em vários processos metabólicos relacionados á nutrição e a utilização de estratégias nutricionais, pensando em nutrientes como cofatores e os compostos bioativos como "Starters" da expressão de genes protetores e silenciadores de genes patológicos, colocarão o Nutricionista como um dos profissionais mais importantes na busca pela longevidade e na promoção da saúde da população;

- A importância da nutrição na Genômica Nutricional (Nutrigenômica e a Nutrigenética) e na Epigenética, podem determinar no futuro, a diferença entre o risco de doenças crônicas e a proteção do organismos contra as mesmas. É claro que sabemos que vários fatores externos se relacionam à saúde do indivíduo, mas nenhum destes fatores se torna tão importante quanto a alimentação, se levarmos em conta que esta, está presente várias vezes durante todo dia, ao longo de toda a nossa vida;

- A Nutrição projeta para o futuro, a remissão de doenças crônicas, a programação metabólica das expressões gênicas e a modulação hormonal, por meio de uma alimentação adequada e individualizada, equilibrada em compostos bioativos, como uma realidade cotidiana de profissionais de Nutrição, que terão uma conduta clínica baseada em exames genéticos e na bioeficácia nutricional, transformando o nutricionista em um Consultor Nutricional, indispensável para o desenvolvimento da saúde humana;

- Sendo assim, podemos afirmar que desde a Nutrigenômica até o network biológico das interações entre nutrientes, compostos bioativos e a genética, a Nutrição se destaca como uma ciência de infinitas possibilidades, e se tornará, em um futuro próximo, o conjunto de conhecimentos científico, mais complexo e necessário para o controle e remissão de doenças crônicas não transmissíveis, por meio da programação metabólica das expressões gênicas e a modulação hormonal pelo alimento;

- Uma conduta individualizada e equilibrada, baseada na avaliação complexa dos exames genéticos será indispensável para o desenvolvimento das potencialidades humanas e modulação de genes para darmos condições 
à humanidade de ser capaz de atingir plenamente todas as suas potencialidades e fará da nutrição o conjunto de conhecimentos científicos, mais complexo e necessário para o controle de doenças crônicas não transmissíveis.

\section{Referências bibliográficas}

1. MOZAFFARIAN, D. et al. History of modern nutrition science-implications for current research, dietary guidelines, and food policy. BMJ 2018;361:k2392

2. DE LUCA, L.M. ANDA NORUMM, K.R. Scurvy and Cloudberries: A Chapter in the History of Nutritional Sciences. American Society for Nutrition. 201

3. VIDAL, M.; CUSICK, M.E.; BARABÁSI, A.L. Interactome Networks and Human Disease. Cell; 144, 2011.

4. BARABÁl, A.L. Network Medicine - From Obesity to the "Diseasome". The New England Journal of Medicine, 2007

5. MENCHE, J.; SHARMA, A.; KITSAK, M. et al. Uncovering disease-disease relationships through the incomplete human interactome. Science; 347(6224), 2015. 